\title{
Assessment Of Morphological Analysis Of Iraqi Traditional Courtyards Houses
}

\author{
Hayder Jawad Shakir Haraty ${ }^{1, *}$, Mohammad Yazah Mat Raschid ${ }^{1}$, and Mohd Yazid Mohd Yunos ${ }^{2}$ \\ ${ }^{1}$ Department of Architecture, Faculty of Design and Architecture, Universiti Putra Malaysia, 43400 UPM Serdang, Malaysia \\ ${ }^{2}$ Department of Landscape Architecture, Faculty of Design and Architecture, Universiti Putra Malaysia, 43400 UPM Serdang, Malaysia
}

\begin{abstract}
The traditional Iraqi courtyards house demonstrates fundamentals principles in term of construction, its spatial organization and design can be compared with the modern home. The research claims the current housing design in Iraq does not fulfill the cultural and the social need of their residence; the traditional courtyard houses have manifested that in the uniqueness form in the plan. This research attempts to analyze the historical and traditional courtyard house as the arisen construction of houses in Iraq. The research objective is to document the architectural forms of the courtyards houses in Iraq. The form of the house is one of the aspects to be studied and understood as it measures and establishes the architecture design concept of these dwellings. Morphological study on the form of eight case studies of the Iraqi Traditional Courtyards Houses has been utilized. The aim is to discuss and inspect the uniqueness of these units that served their residences for decades. Additionally, the author used computer software (AutoCAD and 3d Max) to redraw the cases to be more representative. The study's significance is to add a distinct understanding among designers, planners and decision-makers to put into consideration the future architecture of houses design and to preserve the traditional houses from vanishing. The findings revealed that privacy has a great influence on the design layout of the traditional house which presented in the simplicity of design and the separation between zones.
\end{abstract}

\section{Introduction}

The courtyard house represents a model for the collective social, political and economic benefits. It is the architectural mass type harmony, which depends on its plan's conformity. The various types of courtyards houses characterize the harmony recurrence of the plan and shape. It was able to secure a large group of social functions to both residents and visitors. It allowed both privacy and participation in the clan and extended family levels [1]. The courtyard house provided an ideal space for the social interactions among the nuclear families and visitors, perhaps women most especially [2]. The architecture has symbolic significances probably including much physical meaning [3]-[6]. The courtyard plays a central role in the daily life of the family. It is the place where family activities take place without their privacy being diminished by overlooking adjoining dwellings [7]. The Iraqi courtyard house served both physically and symbolically, and it was the most appropriate space of a family [8].

The design concept of the traditional house, problems, and solutions can be traced in many of the existing traditional Arab architecture, in which habits and traditions dictated forms and spaces. The Iraqi traditional courtyards house was the popular pattern of housing design in Iraq until its disappearance [9]. Unlike the architecture of the cities in Iraq, the culture of residence was not affected by the revolution of the imposed architecture [10]. The culture of privacy, guests hosting, and segregation is the main obsession of most Iraqis [10], [11].

Houses in Iraq should have certain criteria which are to respect the neighbors' privacy and the guests. Among the criteria are: houses should not exceed two to three-story high, windows should not be looking at the street and gender segregation. However, the traditional courtyards house was the standard form in the MiddleEast region such as Turkey and Iran [12]. Additionally, the traditional courtyards house flourished from people culture and necessities over the years; its physical form was the ideal for the socio-cultural needs of Iraqis and the Middle-East [12].

\section{The Iraqi courtyard house dilemma}

The traditional courtyard house was the essential form in Iraq before its disappearance in the 20th century. The issue of housing is universal, however; its epidemic in Iraq. Previous studies described the main issue of the misconception of the contemporary house that the current design does not fulfil resident's needs, functionally and traditionally [13]. Some of the elements which created the uniqueness of the Iraqi traditional courtyards house have been missing in the architecture

* Corresponding author: hayderharaty@gmail.com 
housing [14]. Private spaces such as the segregation between the guest's room or the family spaces have been neglected. Also, the failure in generating spaces and a suitable house that are carrying the social demands and the religious needs, this might affect negatively on the residents and their daily activity [15]. The Iraqi courtyards house is an important form that has served the residence essentials for decades, it has responded to their religious, cultural and social activities [16].

\section{Methodology}

A morphological study is a qualitative approach which deals with shape, size, height and layout [4], [9], [17]. Studying these elements help to understand the development and composition of a structure [18]. A study [10], [19] showed that morphological study had been used to analyze the traditional residential houses; the criteria utilized were: size of spaces, location, and the spatial organizations of rooms.

The classification of the case study selection was based on the development of the courtyards house, especially the construction level. Eight cases selected to be more representative in this research. The parameters which were used are the size of the unit, exterior design, room distribution, and the unit height. Each case has its uniqueness that was presented in the exterior form and the architecture. Two computer software were utilized to illustrate the $3 \mathrm{~d}$ form and the exterior of the selected units, 3dMax and AutoCAD used for that purpose. The selection of cases studies based on the development and complexity of the courtyard space which started by a simple rural house and ended with an urban complex unit.

\subsection{Rural Courtyard house}

The house is one story height that located in a rural area. The house has a very simple architecture with only a few rooms scattered around the courtyard. It is a farmer house with single family. The overall form of the house is square with an irregular courtyard area. There are two entrances, one from the south and the other from the north; the area of the house is considerably large with 20 x 20 square meters. Functional rooms such as the bedrooms and the guest's rooms unevenly distributed around the courtyard. There are no such cantilevers, windows or any opening on the exterior.

\subsection{Rural Courtyard house in Baghdad / Al- Kadhimiyeh}

The second case study is located to the south of Iraq. It is divided into two parts. The first part is designed for the farmer family and its simple with one floor, whereas the second part is the owner space and his family that it is two-story high. The house exterior is irregular in shape, and the courtyard space is square. The area of the house is significantly large with an area of $30 \times 30$ square meters. The rooms and spaces evenly distributed around the courtyard space. The house has a clean exterior design [9].

\subsection{Simple urban courtyard house in Baghdad $1 / 54$}

This case study represents the early development of the Iraqi traditional courtyard house. The house located in a dense city that is surrounded by houses. The unit is twostory high. One family was living in this type of house. The house and the courtyard are both regular in shape with a bumpy ceiling. The size of the house is $30 \times 30$ square meters. The rooms are distributed evenly around the courtyard from all sides. However, the facade of the house has few openings on the ally [20].

\subsection{Complex urban courtyard house in Karbala I Shamad Danla house}

This house represented the first move toward complexity in design with multiple courtyards in one house. The house is two-story high. It has two regular courtyards; one small and the other is large. The segregation between the family and the guests presented by dividing two courtyards for more private space. The size of the dwelling is 35 x 50 meter with linear form. The house spaces evenly distributed around both courtyards. The exterior shape is irregular, windows and cantilevers designed on the ally. The house belonged to a very wealthy family, hence the complexity in the form of the house.

\subsection{Urban courtyard house in Babylon / Hussien Bik house}

The other example of Iraqi traditional courtyard house located in limited available land. The house form is linear, the fact that the limitation of land gave this unit its uniqueness. Its form showed that the courtyard space does not always require significant space to build. The house outline is an irregular shape with regular courtyard form. The unit is Two-story high. The house size is $10 \mathrm{x}$ 30 square meters. The distribution of rooms concentrated on the front and the end side of the house. A lattice wooden windows shanasheel placed at the first-floor facade.

\subsection{Modern architecture courtyard house I Baghdad}

This house belonged to one of the wealthy families in Baghdad; it is currently a hotel. The form of the house is significantly involved and more substantial than any of the previous cases. There are two courtyards spaces and multiple entrances. The unit is two-story high. Also, the house is looking at the Tigris river with open space (not surrounded by other houses). The size of the house is 40 $\mathrm{x} 100$ square meters. The smaller courtyard is regular in shape whereas the other is not. The exterior form decorated with many openings and cantilevers. 


\subsection{Urban traditional courtyard house in Baghdad / Mnaheem house}

It also belonged to one of the wealthy families in Baghdad. The house exterior is an irregular shape with two constant shape courtyards, the small one is for the guests, and the larger one is the family space. The unit is two-story high. The size of the large courtyard is $30 \times 30$ square meters, and the small one is $10 \times 15$ square meters. More rooms distributed around the family courtyard zone (the large courtyard), whereas the small courtyard has few bedrooms on its sides. The exterior form is clean, few openings at the ally side.

\subsection{Urban traditional courtyard house in Babylon / Murad house}

This example of Iraqi traditional courtyard house has a single courtyard space that significantly large in scale. Although it served the family and the guest, the segregation presented by adjusting floors. The family space is the ground floor, and the guests can use the upper area. The total house area is $30 \mathrm{x} 40$ square meters, and two-story high. The form of the house is simpler, the exterior is clean and does follow the urban fabric.

\section{Discussion}

The parameters used in the form analysis include; house location; the number of courtyards, simplicity in design, house size, story-high, and the rooms distribution. The analysis of the eight cases studies revealed that the overall form is a simple shape; however, the complexity of the house followed the family wealth and the location. The geometrical form of the houses is rectangle or square and vary in sizes. The Heights of the houses are different which did not exceed two-story high. The outline of the exterior is following the fabric design of the city and mostly irregular in shape.

Additionally, the morphological analyses of the Iraqi traditional courtyard houses have revealed that the form is simple in design especially the example of rural courtyard houses in case one and two. However, the developed case studies with bigger courtyards houses have shown a significant variation in form with more complicated construction but did not exceed two-story in height such as the example of cases four, six and seven. The previous studies stated that family wealth has the significant impact on the architecture of the Iraqi traditional courtyards house [21]; however, aspects like privacy and welcoming guest remain untouched as the essential values of Iraqis. The variation of multiple courtyards also utilized for privacy purpose.
Table 1. Morphological analyses on the form of the Iraqi traditional courtyard house. Source. Author

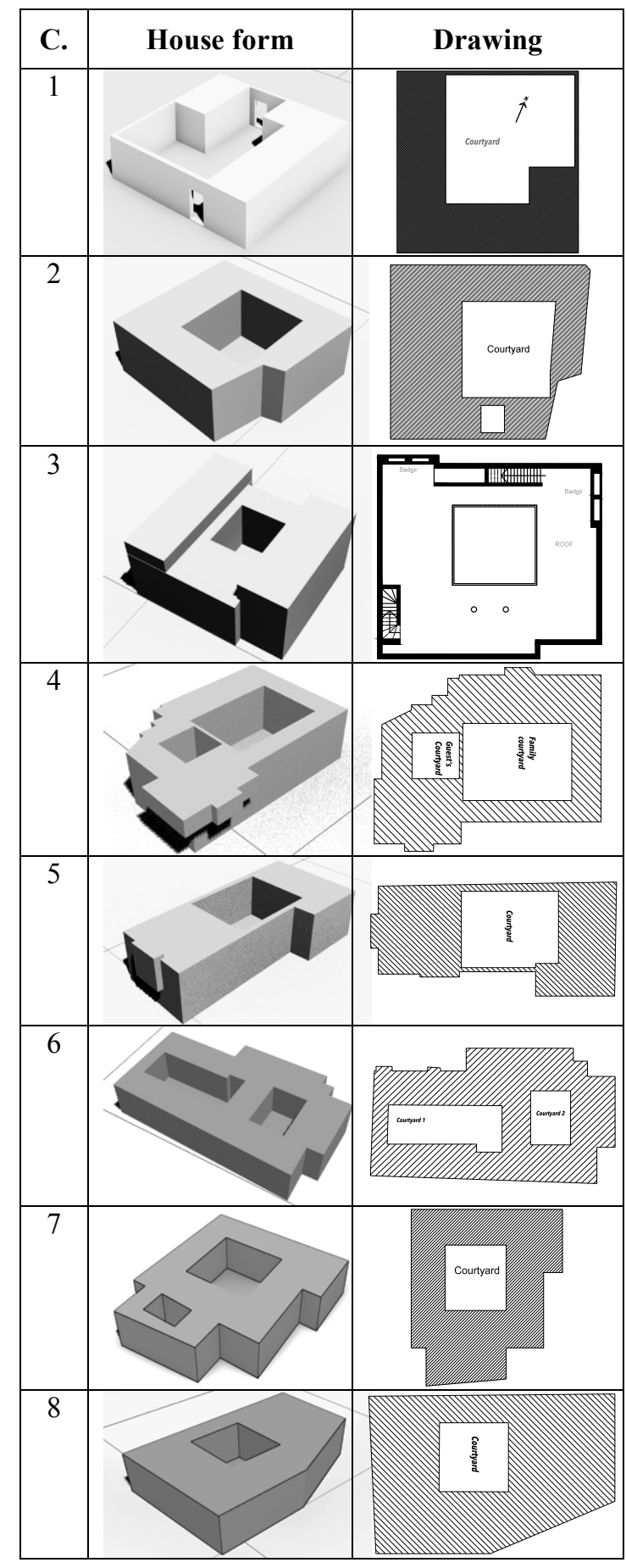

\section{Findings}

The heights of the houses remained low which is not to violate the neighbor's privacy. The overall shape of the traditional courtyard houses is simple and has clean façade exempted from any decoration especially on the ground floor level. The majority of case studies showed significant simplicity in design. The culture of Iraqi showed that it is vital to have separated spaces between the family and the guests. The socio-culture of Iraqis mainly concerns about the privacy. 
Moreover, the analysis has shown the adaptivity of the traditional courtyards house vary and could be used for many occasions. One major advantage of having a traditional courtyard house is that the simplicity in design eliminates the unnecessary objects that might increase the construction cost. Also, it enhances the privacy level of the residences and the neighbors. However, the disadvantage is that such a construction requires significant land area which could not be available nowadays and it can be costly. The neglection of this monumental architecture could result in loss of identity and result in distortion in future designs.

\section{Future studies}

It is recommended to implement more case studies of Iraqi traditional courtyards house. Future research should focus on the spatial organization of rooms and the methods that researchers used to respond to resident's needs. Future architects and planners must consider the preservation of the traditional house to generate more responsive layout to people identity.

We thank "anonymous" reviewers for their comments on an earlier version of the manuscript, although any errors are our own and should not tarnish the reputations of these esteemed persons. The author would like to express his gratitude to The University of Technology, Baghdad for providing access to references and materials.

\section{References}

1. A. Alhusban and A. Al-Shorman, "The Social, Political and Economic Functions of Courtyard Houses in Umm Qais, Northern Jordan," Int. J. Hist. Archaeol, 15, pp. 1-9,(2011).

2. A. El-Shorbagy, "Traditional Islamic-Arab House : Vocabulary And Syntax," Int. J. Civ. Environ. Eng. IJCEE-IJENS, 10, 4, pp. 15-20, (2010).

3. R. Othman, Zulkeplee, Buys, Laurie, \& Aird, "Home and the Embodiment of Privacy," in TS+B1 (Time, Space and Body) Global Conference, 2013, p. 13. 4. S. AI-Azzawi, "Indigenous Courtyard Houses," Renew. Energy, 5, 2, pp. 1099-1123, (1994).

5. O. Q. A. Alchalabi, "Genetic Shape Plan of The Traditional Ottoman's Style House," Al-Rafidain Eng., 20, 5, pp. 148-164, (2011).

6. W. K. Al-Hemaidi, "The metamorphosis of the urban fabric in Arab-Muslim City: Riyadh, Saudi Arabia," J. Hous. Built Environ., 16, 1, pp. 179-201, (2001).

7. O. Spahic, "Towards Understanding Islamic Architecture," Islam. Stud., 47, 4, pp. 483-510, (2008).

8. S. M. Sharif, M. F. M. Zain, and M. Surat, "Concurrence of Thermal Comfort of Courtyard Housing and Privacy in the Traditional Arab House in Middle East," Aust. J. Basic Appl. Sci., 4, 8, pp. 40294037, (2010).

9. O. Reuther, Das Wohnhaus in Bagdad und anderen Städten des Irak. Berlin: Wasmuth, (1910).
10. H. J. S. Haraty, M. Y. M. Raschid, and M. Y. Mohd Yunos, "Traditional Iraqi Courtyard Houses Morphology: An Islamic Point of View," in UMRAN2015: A Vision of Establishing Green Built Environmrnt, 2015, p. 356.

11. M. Hussein, "From Courtyard To Monument: Effect of Changing Social Values on Spatial Configuration of "The Cities of the Holy Shrines " in Iraq," in Proceedings of Ninth International Space Syntax Symposium, 2013, p. 038:2-038:23.

12. H. J. S. Haraty, M. Y. M. Raschid, and M. Y. Mohd Yunos, "Morphology of Islamic Traditional Iraqi Courtyard House Toward Holistic Islamic Approach in New Residential Development in Iraq," in Complexity in Applied Science and Engineering International Conference (CASEIC 2017), 2017, p. 23.

13. N. Yu, "The Urban Courtyard Housing Form as a Response to Human Needs, Culture and Environment," The University of Guelph, (1999).

14. G. H. Memarian, S. Oljerdi, and A. Kermani, "Privacy of House in Islamic Culture: A Comparative Study of Pattern of Privacy in Houses in Kerman," Int. J. Archit. Eng. Urban Plan. Priv., 21, 2, pp. 69-77, (2011). 15. A. P. Amlashi, S. Y. Mousavi, and A. Falakian, "The characteristics of suitable home from Islam point of view in comparison with Modern architecture," Int. Res. J. Appl. Basic Sci., 4, 5, pp. 1312-1318, (2013).

16. J. A. Akbar, "Support for Court-yard Houses Riyad, Saudi Arabia," Massachusetts Institute of Technology, (1980.)

17. O. Aineias, "Bioclimatic elements and design principles of the traditional architecture in northern Greece," in PLEA 2008 - 25th Conference on Passive and Low Energy Architecture, 2008, 269, pp. 25-29.

18. N. J. Habraken, "Type as a Social Agreement," in Asian Congress of Architects, 1988, p. 18.

19. I. W. Susilo, "The Living Culture and TypoMorphology of Vernacular-Traditional Houses in Kerala," (1969).

20. A. Al-Haidary, The Baghdad House. Al-Mada P.C., (2008).

21. B. Edwards, Courtyard Housing: Past, Present and Future, 1st ed. Taylor \& Francis, (2006). 